\title{
Message from the Principal
}

It is my great pleasure to lunch the second volume of Journal of Business and Social Sciences (JBSS)-2018 issue to the readers. I promise, at HSM, you will not only get degrees or academic excellence but also important life values like discipline, hard work, sincerity, leadership, confidence, and professionalism. In addition to that, HSM has started to create the platform for the research related work that may fulfill the gap of theory and practice.

JBSS is a new broadscope publication aiming to publish high-quality research and expert knowledge on topics that guarantee the functionality of the building stock throughout its service life.The journal has a strong emphasis on interdisciplinary issues as we're conscious that many complex problems in the built environment require multidisciplinary solutions. Interdisciplinary research is often difficult to publish in specialized journals and part of JBSS aim is to capture highquality work that doesn't clearly fall within the remit of other journals focusing on research related to the built environment.

Moreover, outstanding academic performance in diverse streams has been made possible by its qualified, dedicated and professionally competent teachers and devoted students, supported by the cooperative administrative staff and managerial team of the college. It has been hoped that this journal will boost up the quality of the dedicated faculties of HSM and help to upgrade the existing body of knowledge that can be transferred to the students, academicians as well as society.

On behalf of HSM family and as a head of the institution, I am heartily thankful to authors, advisory board members, peer review \& editorial team, managing editorial team, administrative officials, research department, publishing press and all the associates of JBSS. Errors are vital for progress and improvements, thus I would take the responsibility and accountability of JBSS 2018 issue. I always welcome the constructive innovative ideas that can make my students happy.

At the end, I will promise to you all the readers that, in the days to come, JBSS will improve more on its ranking, indexing, and quality. The future plan of JBSS is to touch the height of international standards. Let's join HSM journal, work together, feel together, and contribute together.

We look forward to welcoming your submissions in 2019 issue.

Regards

Puran Bahadur Joshi

Principal, HSMSS

Journal of Business and Social Sciences (JBSS) 